\title{
Public-Private Partnerships and the Prospects for Sustainable ICT Projects in the Developing World
}

\author{
Elizabeth Fife and Laura Hosman \\ University of Southern California, United States
}

\begin{abstract}
This paper analyses the recent phenomenon of private/public partnerships (PPPS) in the ICT sector of the developing world. The partners may come to these projects with divergent motivations: profit on the one hand and the provision of public services on the other, but at the end of the day, the interests of the partners that are symbiotic can - and indeed should - be aligned to ensure successful long-term projects. To investigate what can be done to promote successful and sustainable PPPs, this paper extends the traditional two-actor analysis to include both a third-party non-profit-oriented facilitating organization and the technology recipients that are the targets of these projects. Following an overview of the current state of PPPs in the developing world, the paper provides two case studies, based in Vietnam, where all four of the above-mentioned stakeholders were involved. The cases reveal important success factors that can be applied to future PPPs in the ICT sector.
\end{abstract}

\section{Keywords}

Private/public partnerships, developing world, ICT sector, Vietnam

\section{Introduction}

The recent upsurge in Public-Private Partnerships (PPPs) between developing country governments and private firms is especially prominent in the information and communications technology (ICT) sector. These joint projects are undertaken in an attempt to bring the benefits of technological efficiencies to the developing world, taking advantage of the strengths and interests of each partner. However, the underlying motivations for the individual partners can be widely divergent: one is driven by a profit motive; the other by the desire to deliver social services to constituents. Even so, it is possible, and vital, to attempt to align these partners' interests, to promote the important task of bridging the digital divide.

This paper addresses the following questions: How can these divergent motivations be aligned

Copyright (C) 2007 Victoria University. This document has been published as part of the Journal of Business Systems, Governance and Ethics in both online and print formats. Educational and non-profit institutions are granted a nonexclusive licence to utilise this document in whole or in part for personal or classroom use without fee, provided that correct attribution and citation are made and this copyright statement is reproduced. Any other usage is prohibited without the express permission of the symbiotically to ensure a win-win scenario, not just for the parties mentioned, but for the recipients as well? Along the same lines, what are the prospects for long-term sustainability of these projects, and what can be done to promote this? One method brought forth in this paper involves bringing two important actors into the analysis: both the recipients of the technology, and a third-party organization 
- one with no profit motive - that can initiate and cultivate relationships between the public and private partners and function as an intermediary in the contract-forming process. This is the role that a governmental, non-governmental, or inter-governmental organization such as the World Bank, the United States Agency for International Development (USAID), the Australian Agency for International Development (AusAID), or the Catholic Fund for Overseas Development (CAFOD), often plays.

Involving an intermediary most directly addresses the initial stages of the PPP's formation, but if contracts are well-formulated and roles made clear from the outset, it can go a long way toward addressing the longer term prospects of the venture. Additionally, it is often people working for such organizations that prioritize involving the recipients of the technology in the process, by asking the opinions of local residents, instead of assuming that they know what is best. To our knowledge, these topics have not yet been addressed within the still-nascent scholarly literature on PPPs in the ICT sector.

Our paper proceeds as follows: after an overview of the emerging public-private partnership trend in the information and communications technology sector and a discussion of the diverse motivations facing the public and private actors, a brief theoretical discussion appears. Next, we provide a more specific and comprehensive look at current projects and initiatives underway involving Western technology corporations and the developing world, followed by a section presenting the major challenges facing such projects. The following section introduces the concept of a role for a third party intermediary in the PPP scenario. We follow this section with two timely case studies, which involve bringing telecommunications and broadband technology to remote, rural villages in Vietnam. These cases involved a public private partnership as well as the presence of a facilitator. Following the case studies, we conclude with an overview of success factors, and a call for future research.

\section{Overview of Global Public-Private Partnerships in the ICT Sector}

Over the past few years, the growth of private investment for development has been remarkable in magnitude, as has private enthusiasm for public partnerships. The proportion of funding from the U.S. government relative to that from private enterprise has shifted in recent years, with 85 percent of resources now coming from fixed capital investment, remittances, and other forms of non-governmental giving. Some 15 percent of resources transferred from the U.S. to the developing world come from Official Development Assistance (ODA). In the 1970s the breakdown was nearly the opposite (Runde 2006). In the next few years, the annual investment into the ICT sector in the developing economies could reach $\$ 100$ billion.

Ideally, public-private partnerships are thought to create synergistic results by combining the expertise and resources of the private partner with the administrative and political power of the governmental partner. They can take several forms, but are usually viewed as a business relationship, or agreement, between two or more parties that combine private sector capital (and sometimes public sector capital) to improve public services and the management of public sector assets (Gerrard 2001).

Current ICT sector PPPs seek to define and address a development challenge. These partnerships enjoy broad support and are promoted by governments, international organizations (such as the World Bank, the United Nations Development Program, the UNCTAD and others), non-governmental organizations (NGOs), and private firms alike. Because there are numerous potential benefits - increased efficiency and scalability of projects, financial resources, human capital, technology and intellectual property, market access, cutting-edge business practices, and other expertise - when both public and private actors join forces, these partnerships are coming to be seen as the most efficient method for bridging the digital divide. In fact, the United Nations Millennium Declaration specifically recommends the creation of public private partnerships to "ensure that the benefits of new technologies, especially information and communications technologies... are available to all," (Weigel \& Waldburger 2004, p. XV).

From a corporate point of view, what could be more ideal than doing good while doing business contributing to ICT connectivity around the globe while simultaneously contributing to the bottom line? 
From a developing country point of view, what could be better than to have infrastructure, hardware, software, and expertise all provided by a world leader in technology, with the implicit promise of bridging the digital divide and increasing efficiency and economic growth? Herein lies the attractiveness and appeal behind the recent surge in public private partnerships (PPPs) undertaken between Western technology MNCs and developing country authorities. And there is good reason for this appeal: When these projects are successful, they can bring about many desirable benefits.

Yet, the academic community reports mixed results for such undertakings. One major concern regarding PPPs in the developing world - particularly in rural communities - is that they do not address the larger issues of socio-economic development and poverty eradication. Kanungo (2004) reports that private sector participation in such projects has not demonstrated better results than previous public sector initiatives. A further concern is the sustainability of such projects: if they do not prove to be profitable for the private partners, will they abandon the projects? Alternately, do the projects provide for sufficient local training to make them sustainable once the technical experts who installed and programmed the equipment return to their homes?

Some critics question the value of the Internet and telecommunications technologies to address the needs of the developing world - why not focus on a nutritional divide, an educational divide, an opportunities divide, or a health care divide? This is the essence of the "bread vs. broadband" debate: Given the more basic needs not being met in poor countries, how much of a developing country government's monies (or any aid efforts, for that matter) should be devoted to technology issues?

While acknowledging the salience of the above argument, we believe the bread vs. broadband dichotomy to be a false one: this paper asserts that when PPPs are well-thought out and designed with the empowerment of localities in mind, they can bring about long-term economic benefit in nearly all of the basic needs areas mentioned above. Broadband connectivity can enable local small business entrepreneurship, tele-education and tele-health capabilities, knowledge of market prices for crops before they are brought to market, and increased knowledge of successful farming techniques. These are some of the value-adding benefits communications connectivity can bring about; but their potential is more likely to be realized if a project is designed with local needs and desires in mind.

The paper also asserts that this subject is worthy of academic analysis because the phenomenon is already taking place: numerous Western-based technology multinationals have already formed publicprivate partnerships to bring telecommunications-based projects to the developing world. And it is a cause for concern that, to date, there has been a lack of systematic, unbiased research guiding and/or assessing the significant and growing amount of activity in this area.

Little is known about the operation of the public-private model; systematic evaluation is difficult. This may be due to the uncoordinated dynamic of public-private partnerships; there is no central organizing body, projects may be non-comparable on a global scale, and there are no standard metrics for assessment - perhaps due to resistance to evaluation processes in general (Rosenau 1999). Further, benchmarking is seldom done prior to the commencement of a project, and long-term evaluation is most often not a part of the overall budget.

However, if this phenomenon is not studied, the academic community is implicitly accepting that the corporate social responsibility implied in such partnerships - "making a profit and making the world a better place do not have to be mutually exclusive goals" (from AMD's website) - has undergone a change in its very nature, and as such, can proceed, unmonitored and blindly trusted. Yet, history has demonstrated that corporate self-regulation does not always produce ideal outcomes: community- and opportunity-building, empowerment, and increased human well-being in investment-targeted communities may not be at the root of corporate initiatives.

It is important to remember that the venture partners come to the project with different expectations, goals, backgrounds, mindsets, and ways of "doing business;" all of these need to be made clear, as does the plan of action. After all, private firms are businesses run for profit. In this case, the profit from their endeavours often comes later, as current investments help to create future markets. Though private 
enterprises view financial viability as the primary legitimacy in a PPP, the public partner may view local appropriateness and public (electoral) support as overriding in importance (Angerer \& Hammerschmid 2005).

Despite these differences, one commonly cited best practice for firms, within the context of developing country PPPs, may bode well for localities targeted by the project: taking into consideration the needs and desires of the local communities and involving local citizens in all stages of the PPP undertaking - a bottom-up rather than a top-down approach - will lead to more successful outcomes for both parties. In other words, only if the technology catches on and people see a benefit in their lives because of it - if the project is truly a success as the community defines it - will a market for future goods have been created.

\section{Diverse Motivations and Theoretical Discussion}

Many rationales exist to explain the recent upsurge in public private partnerships. This section outlines the wide range of motivations of the public and private sector partners.

For the public partner, PPPs offer attractive advantages, such as increased private finance and investment, technological experience and expertise, risk-sharing, the public legitimacy that results from being associated with a successful global corporation, and a potential downsizing of the public sector or a decrease in governmentally subsidized programs. A further argument for PPPs on economic grounds concerns the benefits associated with a liberalizing of regulations and markets (at least in the telecom sector), increased exposure to technology and more efficient ways of doing business, and a stronger incentive to adhere to the policies of fiscal discipline required to do business with global companies. An additional motivation for governments, and certainly for the recipients of the technology, is the valueadding potential of ICT, not just in terms of economic growth, but also through improvement of social and political capital.

Possible negative outcomes for governments include asymmetries of power and information, and political and financial risks in the event of failed projects. Even so, citizens' increase in demands for governmental services, paired with stagnant government revenues, points to the likelihood of more PPPs being created in the future, particularly in developing countries.

For the private partner, advantages include access to new markets, risk-sharing and uncertaintyreduction, and an improved image as a result of their "philanthropic" work. As stated above, ICT firms are looking to the developing world for new markets. Though activities are directed toward future profits, enterprises are experiencing immediate tangible benefits that are not necessarily related to profit margins. Among these are improved morale among their workforce and the creation of a positive company image both at home and abroad.

Company executives accept low margins in developing markets and acknowledge the long-term nature of current investments in emerging economies. Although these markets will not change the companies' balance sheets for 10-15 years, it appears incontrovertible that this is where the future markets will be and they must get an early foothold in the market to avoid the possibility of being shut out. The search for new markets underscores a point raised by Bruno Lanvin (2005) of the World Bank, who states that:

The arithmetic of telecommunications and that of poverty do not necessarily seem to agree. For a poverty fighter, the 'next billion' would refer to those who need to be taken out of absolute poverty; for an IT executive, the 'next billion' would more spontaneously refer to the next wave of customers that could emerge from developing countries, particularly in the mobile market (p.15).

He finds, nonetheless, that the one billion for whom ICTs are not a priority (those at the bottom of the ladder) and the one billion that the industry is looking to as their next consumers, are not one and the same. Helping both groups to gain access to ICTs is not an impossibility, as long as there is a shared sense of responsibility among the public and private sectors (Lanvin 2005). 
In fact, it is not only private firms that are making the push for ICTs. Governments are also soliciting foreign direct investment to improve the level of and economic growth and competitiveness, and to foster greater inclusion in the global economy. Accordingly, one area in which there has been a global trend towards market liberalization is the telecom sector; the mobile telephone industry has experienced meteoric growth in developing countries. Levels of Internet connectivity and adoption have not grown as rapidly as those of mobile telephony, but have been substantial nonetheless.

While de-monopolization of the telecom sector may be seen as a step in the right direction, it is only the first step: countries that have liberalized must subsequently promote real competition and transparent business practices, as well as shift their focus to regulation and tax reduction. In addition, governments must promote universal access, as well as connectivity in rural areas, e-learning and e-health initiatives: such provisions for the common good are seldom - if ever - provided by an unfettered market. Although the ITU (2006) reports that regulations governing the provision of universal services in basic telecommunications now exist in most countries, whether or not these services are being implemented is a separate issue with which many governments of developing countries struggle. The case studies in this paper provide an example of Vietnam's experience implementing its newly legislated universal service obligation and offer insight to countries facing similar situations.

Academic research on the subject of Public Private Partnerships has revealed cause for cautioned optimism: There are numerous cases of failed PPPs. Despite being touted as a panacea, PPPs are often misunderstood and work well only under certain conditions. Because of this, a good deal of organizational and instructional literature has appeared with the goal of enumerating and promoting best practices involving PPPs, to ensure successful joint ventures (See, e.g. United Nations Foundation 2003, Weigel \& Waldburger 2004, World Bank 2003, 2006). Most of the recommendations put forth in this literature are based upon case study. There is value in such an approach. However, there is also need for a better reporting of failed cases, as these can be equally as instructional as successful ones.

A theoretical understanding of the nature of PPPs is also necessary, as this may lead to greater insight and more successful projects. This is a complicated undertaking, however, since the focus of ICT ventures are most often multifaceted, and the priorities enumerated may depend upon each participant's point of view. ICT projects comprise such diverse goals as infrastructure development, human capacity training, economic development, and information and communications provision. The multifarious nature of these projects, in fact, underscores the basic characteristic of ICT as an enabling tool, and not as an end unto itself.

Despite the complexity of such undertakings, one theoretical basis through which PPPs may be better understood involves a rational choice approach, and sees PPPs as contracts that may change or evolve over time. Accordingly, bargaining theory sees contractual negotiations as a series of games, performed over time, between two rational actors. The games are not zero-sum, since a contractual agreement offers the opportunity for both sides to realize a mutuality of interests, and can lead to a larger share of the final pie to be divided between the players. In other words, both sides can profit from the interaction.

If the above description of PPP contracts being a result of a bargaining game is apt, then two additional points are worth making. First, since the developing country comes to the bargaining table with markedly less experience in negotiating business ventures and less expertise in the telecom industry in general, the presence of a third party intermediary may help to level the playing field, particularly in the most critical initial stages of negotiations. Second, if one views the negotiations through a game theoretic lens, this exercise has the benefit of forcing each player to disclose all of its stated and unstated assumptions, beliefs, and intentions. It ultimately allows the players to see the situation more realistically - from all points of view and not just from their own. Once again, the presence of a third party intermediary in the role of "honest broker," - one whose interest lies in putting together a sustainable project but not in profiting from it - may aid in this scenario as well. 


\section{Current Developing World Partnerships in the ICT Sector}

The emergence of public-private partnerships between ICT companies and the governments of developing nations are increasingly formed with the support of international organizations like the USAID, the World Bank, and the UN. For example, a recent World Bank report advocates that developing country governments work across departments and partner with private enterprise to extend the use of ICT (World Bank 2006).

In 2002, UN Secretary-General Kofi Annan challenged the technology corporations of Silicon Valley (California) to do more in the Public/Private partnership arena; to unleash their creative energies to bring wireless technologies to the developing world and narrow the gap between the technological "haves" and "have-nots" (Annan 2004). Accordingly, chipmakers Intel and Advanced Micro Devices, (AMD) among others - notably Cisco and Microsoft - have initiated programs to distribute low cost personal computers (PCs) to the world's poor. These companies are investing billions of dollars in marketing and research to develop markets in Latin America, India, China, Southeast Asia, and Eastern Europe. Maturing markets in the U.S., Japan and Europe have spurred companies to look to future growth areas (Detar 2006).

Worldwide PC sales are estimated to grow 10.5 percent in 2006, as compared to the 6.8 percent estimate for the U.S. (Detar 2006). Since many technological advancements of the past few decades appear to have deepened the digital divide, ICT companies are taking a different approach this time; in addition to experimenting with pricing models and distribution tactics in the developing world, they are also piloting programs to meet basic social and economic challenges. Education, medicine, and work training initiatives have been established with an eye to future markets

This emphasis on addressing basic needs represents a paradigm shift: in the past, basic improvements in daily life - when they took place at all - were assumed to be a by-product of multinational involvement in an emerging market. The enthusiasm of governments and non-governmental organizations to support private enterprise-led projects also marks a significant change in perspective regarding corporate involvement in growth plans.

Some corporate ICT Chief Executive Officers (CEOs), like Andy Grove and Craig Barrett of Intel, are eager to participate in UN-sponsored conferences that focus on expanding access and more recently on Internet governance, such as the World Summit on the Information Society (WSIS). Ambitious plans such as MIT/Nicholas Negroponte's "One Laptop Per Child" (OLPC) program are often announced at these venues.

Substantial private industry investments have been proposed and are already underway. Microprocessor manufacturer AMD, for example, is in the second year of its $50 \times 15$ initiative, which seeks to provide Internet access to half of the world's population by 2015. About 15 percent of the world's population presently has Internet access.

Intel is also in the midst of its largest emerging markets initiative. It recently announced its intent to invest over \$1 billion over the next five years to improve Internet connectivity, education, and overall computing accessibility in the developing world. Its 5-Year Objectives for the "World Ahead Program" include training 10 million teachers to use technology in education, and to provide schools with wireless broadband connectivity (Agence France Presse 2 May 2006). The company has built three computing platforms for developing markets; by employing local service providers and computer manufacturers, Intel is able to sell these systems for 20 percent below developed-world prices.

Intel's program will be used in a deal financed in part by the Mexican government and the Mexican Teacher's Union: 300,000 personal computers will be provided to teachers at a cost of $\$ 300$ each. Plans are also underway to promote PC use in Brazil and India. The "community PC" is a PC kiosk plan for providing shared computing in places like India, with the cost of each system estimated to be $\$ 500-\$ 600$ and electrical power provided by a solar-charged car battery. Other plans include providing students with small notebook computers and educational software (Dunn 2006). 


\section{Challenges}

Some of the challenges facing these well-intentioned projects include a lack of global coordination of efforts and the need for greater understanding of organizational cultures among the project partners. Another salient concern is whether the projects are designed with the local citizens' desires in mind, and therefore actually perceived to fill an existing need.

A number of large technology-related companies, such as AMD, Microsoft, and Intel have launched ambitious programs (50X15, Unlimited Potential, and World Ahead Program, respectively) aimed at bringing technology to developing countries. Even the United Nations recognizes that private sector companies are not philanthropic organizations and that public-private partnerships are formed out of self-interest. It is rational, therefore, that corporations tout the activities that bring about positive externalities, and utilize them as a marketing tool - their core objective remains profit.

Of concern, however, is that these large companies might pursue their market-expanding activities solely to bring their own products to underserved markets and to establish a conduit for future advertising revenues. Similar issues arise when ICT corporations bring a single invention to the developing world and tout it as a panacea, regardless of local needs. One example is AMD's current focus on its Personal Internet Communicator, a PC with a 56-Kbps modem, hard disk, and USB ports. AMD reports that their system, which is sold for under $\$ 200$ (without a monitor,) is being used in Brazil, India, Panama, Turkey, Russia and Uganda (Dunn 2006). Another example is the "One Laptop per Child" project spearheaded by the Massachusetts Institute of Technology. This initiative, which aims to provide 150 million of the world's poorest children with low-cost, durable laptops, has raised concerns that the technology may be inappropriate for the intended recipients, in terms of addressing development challenges.

The question remains whether these laptops will create the economic and social well-being that the companies desire. Giving a child a laptop to use in school may be an admirable goal, but equipping the machine with the capabilities to shoot digital video, create music, and chat with classmates may drive the children to think of them more as toys than as learning tools. Additionally, while children may quickly adapt to new technologies, adults may not: are the giant technology companies recruiting an army of instructors to accompany the distribution of their laptops, to oversee the training of educators to use the technology in a productive, meaningful way? There are case studies that suggest this is the case. This paper, however, questions whether sufficient resources exist to address the issues of training, upkeep, connectivity, or repair, that must accompany the 150 million laptops that the "One Laptop per Child" program plans to distribute all over the globe. Without a comprehensive, long-term plan for overall implementation, this project could achieve some measure of success, or "bright spots" in due time, but may not otherwise realize the totality of benefits possible or hoped for.

Another question is whether locally relevant content exists for all of these laptops, and whether the educators prefer to adopt technological teaching techniques. Still other issues include whether these laptops will be seen as handouts, and whether the parents of the children who receive the laptops will sell them on the black market in order to meet more immediate daily needs.

Perhaps there is a better argument to be made for the companies that plan to sell inexpensive PCs on an individual basis. In this case, those who buy them are self-selecting; both interested in and motivated to take advantage of the potential benefits ICT can offer. Indeed, AMD, Intel, and Microsoft are advertising to targeted consumers within China, India, Latin America and Russia (Dunn 2006). At issue here may be the infrastructural and hardware demands required to have a PC with internet capability - which includes having reliable source of electricity. This may serve to exacerbate existing inequalities within developing countries (Oyelaran-Oyeyinka \& Lal 2005), or in other words, create a two-tiered or intra-state digital divide.

Still another challenge facing public private partnerships is created by the institutional and organizational differences brought to the table by each participant. In addition to the divergent motivations discussed above, private sector and public sector methods of doing business can differ 
greatly as well. The public sector participants may be hesitant to relinquish control over projects or share information, while the private sector partner may chafe at the inefficiency built in to public sector methods of doing business. In addition, public organizations accustomed to subsidization may take their time making decisions. Simply put, a mutual lack of understanding of the organizational and procedural methods of doing business may affect the expectations and ultimately the outcome of the venture. The examples above serve to illustrate that it can be extremely difficult to bring even the most wellintentioned plans to fruition.

However, despite all of the Western-minded focus on PCs, laptops and Internet, strong - and growing evidence suggests that the greatest demand for ICT in the developing world remains that for the simple mobile phone. There exists a universal desire to be able to communicate with others, in real-time, by voice. Hardware-oriented corporations may do well to consider this fact when planning their developing world strategies.

The rapid growth of worldwide mobile telephony has served as an encouraging example of the possibilities for technological expansion, even in areas where this service seemed unaffordable. Private enterprise, NGOs, and governments are looking at mobile technology as a means to circumvent resource, infrastructure, and policy constraints that have impeded access in developing markets. Future projects may be re-strategized with mobile telephony over Internet as one answer to the demand question.

Finally, there is a lack of global coordination. This can lead to outcomes that reflect the interests and concerns of the donors, not the recipients. Laurie Garrett (2007) reports precisely this problem in the field of global health. Western donors have focused their efforts so narrowly on AIDS that the top killers in most poor countries - maternal death from childbirth and paediatric death resulting from respiratory or intestinal infections - go unaddressed, even though these are much more basic, easily treated, and preventable problems than AIDS. In the case of global health, virtually no provisions exist to allow the world's poor to say what they want, decide which projects serve their needs, or determine how to adapt these projects to the local environment (Garrett 2007, p. 16). The dangers inherent in imposing a developed technology upon the developing world exist regardless of the nature of that technology.

\section{The Role of a Third Party Facilitator}

This paper does not purport to solve the issues mentioned above regarding public-private partnerships. However, one key ingredient in successful projects notably absent from the existing literature is the concept of the third-party facilitator. This role may be played by an international, governmental, or inter-governmental organization that has no profit motive, such as the United States Agency for International Development (USAID), the World Bank, the US Trade and Development Agency, the Inter-American Development Bank, or various relevant branches of the United Nations. Based on the authors' interviews with USAID associates, this paper will focus on the role played by this organization.

The key factor in this new equation - which now involves multiple actors - is that such an organization plays the role of facilitator or honest broker, and does not carry out the project itself. Rather, it brings together the interested parties and proposes a plan of action for a sustainable project. It may then play a passive or active role in setting up the project, but the time line is finite; at some pre-defined point the facilitator departs, allowing the public and private partners to take over the project.

One salient benefit USAID offers is its contacts in the developing world; it has been active in development work for over 50 years, and in each country has established numerous contacts beneficial to American corporations wanting to do business there but unsure of where to start or whom to contact. In the field of ICT, USAID has played this matchmaking role to large corporations, such as Intel, Qualcomm, and Microsoft, as well as for smaller companies. 
The typical project involves a two week planning stage. USAID assesses the feasibility and local interest for a project, identifies the potential partners, and creates a project proposal. It is at this stage that the agendas and interests of all parties must be identified; this can be helpful in addressing the theoretical issue of all players stating their assumptions and intentions. This organization's involvement also plays a valuable role in addressing local interests, allowing the project a higher likelihood of being a good fit for the locality's needs and desires.

Another role that USAID can play in the developing country is as an advocate for a welcoming business environment. In the case of the ICT sector, USAID has actively advocated for market reforms and liberalization of the telecom sector. It has also advocated for Universal Service legislation, which ensures governmental support for bringing telecom capabilities to underserved and rural areas.

There can, of course, be cases in which this third-party role does not lead to optimal outcomes, and it must not be taken for granted that because an organization is not-for-profit it has entirely altruistic intentions. USAID's motivations include furthering the interests of companies with headquarters in the United States: even if a local company would have been a better match in a private-public partnership, there is a good chance that it would be overlooked.

\section{Case Studies}

This paper provides details of two PPP projects similar in all but the technology implemented. Both projects are being carried out in the Northern Vietnamese region of Lao Cai, and are partnerships between Intel and entities within the Vietnamese Ministry of Post and Telecom - the Vietnam Telecommunications Fund (VTF) and the Vietnam Data Communications Company (VDC). In both cases, USAID facilitated bringing the partners together, with the stated goals of leveraging complementary contributions and forming a partnership that would enhance sustainability and scalability. This section highlights USAID's role, but it is worth noting that AusAID has expressed interest in undertaking a similar project in the Quang Ngai province in South-Central Vietnam, as well as other projects in the future. This is a direct consequence of the success of the cases described below (Owen 2006).

Intel's aim within the Lao Cai project is to bring WiMAX (defined as Worldwide Interoperability for Microwave Access ${ }^{1}$ ) to Vietnam and to expand the potential market for its chip-utilizing products. Additional goals for Intel include fostering economic development by deploying broadband technologies in remote areas and cost-effectively delivering reliable broadband and Voice over Internet Protocol (VoIP) to these regions. Intel's development goals are reflected in the company's World Ahead Program, a five-year, $\$ 1$ billion investment in the provision of technologies to developing countries with intent to improve accessibility, connectivity, education, and content (Intel 2007). In these projects, Intel has provided both hardware and support.

The Vietnamese government's goal in these projects is to provide underserved rural areas with telecommunications access, and to ensure the future flow of public utility funds. The Vietnamese government had recently enacted a universal (telecommunications) service fund to this end, but had not yet disbursed any funds. The projects herein described will serve as models for the deployment of similar projects to be funded by Vietnam's universal service/access funds. The VTF also hopes to establish processes and procedures that will ensure the sustainability and scalability of future projects (Owen 2006). The Vietnam Data Communications (VDC) partner is playing the role of governmental lobbyist, as well as providing much of the hands-on support required for implementation and management; this ensures the projects' operability at the local level.

1 The difference between Wi-Fi and Wi-Max is that the WiMAX specification provides symmetrical bandwidth over many kilometres and range with stronger encryption and typically less interference. Wi-Fi has shorter range (approximately 10's of meters,) weaker encryption and suffers from interference, as in metropolitan areas where there are many users, or when there are obstacles to its line-of-sight. 
USAID's role is to bring the public and private partners together, with the goal of extending telecommunications into rural areas of Vietnam. To this end, it provides critical funding and on-site management. USAID's Last Mile Initiative is its global program - launched in April, 2004 - to bring modern telecommunications infrastructure to farmers and small businesses in rural areas that have traditionally been underserved.

USAID is often able to play the role of matchmaker between public and private partners because it is already "on the ground" in developing countries, involved in various development-related projects, and has a presence - as well as contacts - on a local level. This organization also frequently plays the role of empowerer: it interviews and has dialogues with local residents, both asking people what they want the projects to do for them and educating them as to what the projects can accomplish.

USAID typically begins projects by performing an initial in-country overall assessment of a project's feasibility, defining potential partners and assessing the regulatory situation. Over the following months, the organization formulates a more specific plan for the program, choosing targets with features that make them good candidates for the technology. USAID's Vietnam Last Mile Initiative (LMI) commenced in the spring of 2005 with an initial country assessment, and subsequently embarked upon the project design that was completed in the fall of 2005. Implementation of the nationwide project began in December of 2005.

The first project was to bring WiMAX to the rural, agricultural village of Lao Cai, (the capital of the province of the same name), in the Northern, mountainous region of Vietnam. This village was specifically chosen because of the economic benefit the residents could realize if they were able to communicate inexpensively with their Chinese neighbours just across the border, in order to promote trade. Local people were consulted both prior to and during the project's implementation. In Vietnam there are strong provincial governments that operate within the state's regions, and the head of the Lao Cai People's committee was a local champion of the project; this lent the project considerable local credibility and support.

Technology installed included a base station, nearly 20 fixed-access WiMAX modems, wireless and wired VoIP phones, and related networking infrastructure. The modems were installed throughout the city and region: at the local post office, an internet café, a government office, in secondary schools, health care centres, hotels, and in a farm household outside the city (Intel 2007). At each location a VoIP-enabled phone was set up and linked to the modem, providing both broadband internet access and telephone service at minimal cost and with little complexity. (The VoIP service could also be used with existing analog phones.)

The project moved quickly: implementation-level planning began in January, 2006. By June of the same year, Memorandums of Understanding (MOUs) had been signed between all of the parties, and by the end of September, the first WiMAX deployment at Lao Cai was fully operational (Owen 2006).

Given the success of the first Lao Cai project, all three partners decided to move ahead with the second, which will similarly provide broadband internet access to a rural, mountainous area within the Lao Cai region - the city of Sapa - but in this case, the Internet service will be provided by satellite, using the IPStar satellite system. Deployment was financed by substantial investments already made by the Government of Vietnam (Owen 2006, p. 4).

The city of Sapa was deemed appropriate for this technology implementation because it is eligible for universal service funds from the Vietnam Telecommunications Fund (VTF). Moreover, the deployment in this city was seen as a test case, or demonstration project, to determine whether similar satelliteenabled ICT projects can be established in other rural areas within the country (Owen 2006).

The second project was carried out even more quickly than the first: planning took place in late September of 2006, the deployment was undertaken in November-December 2006, and the project was fully operational by January 2007. This project's hardware included a central antenna to receive satellite Internet, with approximately 10 modems distributed throughout the commune, while wired and wireless VoIP phones and a small number of rugged laptops were also distributed (Owen 2006). 
One of the USAID goals for these projects was to design a program that could be self-sustainable in the longer term, so that further subsidization costs would not be required once the programs were up and running. In other words, if, after the initial investment and start-up costs are incurred, such projects can become profitably run by a local municipality or entrepreneur; ongoing governmental subsidies would no longer be necessary. This concept of long-term sustainability is central to the realization of this and similar projects in the future.

In both cases, Voice over Internet Protocol (VoIP) technology is the primary application provided for voice communications. As a result, both Internet connectivity and voice-related communications are enabled with a single technology deployment. This combined provision of Internet and voice in a single technology minimizes both short term and long term costs, as VoIP presently represents the leastexpensive method of communicating over long - and even short - distances. It also addresses the provision of a service that is currently the most in-demand in the developing world - voice communications - while simultaneously providing Internet connectivity, for which demand may ultimately increase over time.

\section{Successful Outcomes for the Cases}

It may be too soon to comment on the long-term economic and social benefits for the communities involved in the preceding cases; whether the technology has been adopted and used in the health centres and schools to which it was provided, and whether the communications technology has led to economic activity and growth. Even so, the projects have already been deemed successful on several fronts. As such, a number of critical success factors have been identified and can serve as valuable lessons-learned for future projects of a similar nature.

First, the project took advantage of the intersection of interests common to the parties involved. All partners had long-term goals motivating their participation. Next, the project benefited from reliable, committed public partners, at both the local and national level.

As to the hardware requirements of the project, the PPP contracts made clear that resources were not handouts, but were provided in a collaborative/supportive approach (Owen 2006). The project was structured to include a US-based manager as well as one based in Vietnam. Everyone working on the project took advantage of the telecommunications technology made available by the project - email and VoIP - to ensure a continual dialog between participants. Additionally, monthly status reports and thorough periodic project reviews and projections were provided on a regular basis (Owen 2006).

An uncompromising project management approach gave way to a more flexible one once the project got underway, which is often the case when diverse partners come together. However, the compromises that were made never overrode the core interests of any of the participants (Owen 2006). Finally, as mentioned above, all of the participants viewed the project through a long-term lens: USAID acknowledged that their role had an end date; Intel sought to create a long-term market, and the VDC used the project to enhance its position within the Vietnamese marketplace and gain legitimacy among constituents.

The cutting-edge technology utilized in the projects is also noteworthy; its unique and novel attributes show promise for deploying similar projects around the world. This is the case because these technologies have transformed what was once an expensive proposition - providing telecommunications capabilities to low-income, low-density populations - into a much more affordable one.

The Sapa project made use of three noteworthy technologies. Simply described, these are: satellite technology to provide the Internet backhaul (to transport the information back and forth), WiMAX technology to distribute the Internet access on the ground, and Voice over Internet Protocol (VoIP) to enable voice communications. These technologies are both revolutionary and enabling in a number of ways. The specific satellite technology employed in the Sapa project is already being used on a regional basis, serving a number of neighbouring Southeast Asian countries, but in a limited and inefficient 
manner - to single subscribers at elevated rates. Utilizing the same satellite to provide internet backhaul for entire villages provides economy of scale, which results in a more affordable proposition.

The WiMAX technology enables the network to be available across a larger geographical area than was previously possible: a WiMAX omni-directional antenna and WiMAX access points distributed throughout a region enable the satellite-provided WiFi Internet to be available for distances greater than before. With solar-powered modems and WiFi towers now available and being used, a stable source of electricity need no longer be a prerequisite for bringing information and communications technology to underserved areas. Finally, VoIP is the least expensive method of voice communication known today. Enabling residents of rural villages to make both local and long-distance calls at minimal cost provides increased efficiency in planning and communication, leading to economic growth. If governments allow, local communities can become their own telecommunications providers, not reliant upon the central administration for handouts or subsidies.

In the foreword to the influential book ICT4D - Connecting People for a Better World, three areas are identified where immediate action is required: First, to integrate ICT systematically into poverty reduction strategies: Second, to move beyond small pilot projects to larger, nation-wide implementation of ICT programs: Third, to continue to create new types of partnerships involving all major stakeholders - government, civil society, and the private sector (Weigel \& Waldberger 2004, p. 8). The paragraph below gives evidence that these case studies may also be viewed as successes based on their addressing of the enumerated criteria.

As a direct result of the success of the Lao Cai pilot program, a larger initiative has commenced to undertake a similar project in the Quang Ngai province in South-Central Vietnam. The partnership for this program comprises a local (Vietnamese) mobile phone company, the provincial government, AusAID, USAID, and the World Resources Institute. The program is designed with specific applications in order to improve agricultural performance, health care, micro-credit, educational access, and connectivity. Both the provincial government and the local mobile company have indicated their intent to scale the solution across the entire population of the province (one million people), and potentially, across the rest of rural Vietnam. Also stemming from the Lao Cai program's success, Intel approached USAID, proposing to work together to implement this same program in up to 30 different countries (Owen 2006).

\section{The Nexus: Success Factors that Matter}

Re-shifting the focus to the bigger picture, we have identified several practices and/or characteristics common to the successful implementation of ICT projects. These are drawn from previous literature as well as the current case study.

The first is to start out small, even if the project is a partnership between top levels of government and a large multinational corporation. Modest efforts that are in line with local realities and appropriate to local socio-economic conditions are more likely to be adopted by the local residents. Smaller projects are more easily adapted to changing conditions. There can be large returns from low-cost projects, and even successful, scalable projects often begin as pilots, the successes of which may inspire the confidence in both investors and the government to "think bigger."

The second practice is to identify the technology appropriate to the project. Oftentimes, simpler is better. In this case, some of the newest available technologies were utilized, but this had much to do with the local circumstances, including existing satellite availability and the region's mountainous terrain. Also, the technology was deemed appropriate because it brings telephony, at the lowest-cost rates available, while at the same time as providing Internet connectivity. In the end, the choice of technology must be determined by the project's characteristics.

A third characteristic necessary for success is the proper nature of a state's telecom sector: it must be liberalized, with the presence of real competition. Also essential is the government's desire to implement universal telecommunications service. Such was the case in Vietnam. 
A fourth success factor involves finding appropriate partners for the public private partnership. They must all be interested in the long-term sustainability and scalability of the project. In this case, the presence of a third party intermediary proved, by identifying and bringing together the potential partners, to be extremely useful. This actor's focus - not on profits, but on crafting a sustainable project - was particularly fruitful during the contract-formulation stage, when each player involved had to make its intentions and motivations clear. Forming a solid contract tends to benefit all players throughout the life of a project.

The fifth success factor is the recognition that there are more than just two parties involved in a publicprivate partnership. Local communities must be involved from the outset in these projects, so that they will feel like stakeholders in what could otherwise seem top-down, paternalistic, foreign projects. Involving communities includes both inquiring of the residents what their needs and wants are, as well as educating them as to what ICT can do for them. The enthusiasm and commitment of decision-makers is a factor common to most successful cases, and the presence of a local project champion can help greatly with local acceptance, as was the case here. Services that are seen to be useful, and demonstrate their utility quickly, will be used in everyday life, which also encourages adoption. Buy-in by citizens is much more likely if services demonstrate an improvement over the status quo.

Some challenges that remain for the project described above include its ongoing monitoring, to determine whether the technology will be adopted by the local residents. Time will tell whether the people of these cities will take advantage of the technologies beyond their use for simple communications; whether the more advanced areas of information technology, education and health care will be served as well. It also remains to be seen whether, as initially anticipated, the local residents will adopt the ICT to benefit themselves economically. A further challenge exists regarding the financial sustainability of the project: although the government is financially committed to providing universal service, it is preferable that the project be self-sustaining, and the possibility exists for it to become so. Whether this will happen will be seen in time.

\section{Conclusion}

The digital divide was, at one time, considered merely an issue of access. A more meaningful distinction now made is the disparity in real access, defined in terms of both physical access and usability (UN 2004, p.8). Developing a beneficial "culture of use" is most likely to take place when success factors are present - services are visible, frequently used, context specific, have a human face, and meet tangible needs. Systematic benchmarks for measuring progress do not exist, which highlights the need for more organized data collection efforts. ICT investments in the developing world will continue to grow in the coming years. Thus, there is great opportunity for careful investigation of how these resources can best be used to fight poverty.

Progress has been made in gathering information about ICT-related Public Private Partnerships in the developing world. We can identify benefits in the success stories, yet tracking the effects of programs throughout a project's lifecycle is still an important activity that is too often left undone. Additionally, our paper reports two successful cases - a more ideal scenario may have been to contrast a successful case with an unsuccessful one, with or without the presence of an intermediary party. Nonetheless, the multitude of related projects currently underway provides an unprecedented opportunity to learn how social and economic change can be furthered through advanced technologies. The lessons that we learn may be applicable to many contexts. Greater clarity about the underlying drivers of technology adoption throughout the world is an additional part of the fundamental understanding of how technology can best be applied to meet real needs.

Serving the needs of emerging markets offers many challenges and opportunities to the private sector. Developing country governments, and other organizations acting alone, have not been able to mount a comprehensive enough effort to eradicate poverty in the lowest tiers of the economic pyramid (Hart 2005). Public-Private Partnerships thus offer great opportunities for technological advancement in the 
developing world. Still, there is a need for careful study of these initiatives, in order to ensure successful, sustainable projects and to encourage the use of ICT to further human development.

\section{References}

Angerer, D J \& Hammerschmid, G 2005, 'Public private partnership between euphoria and disillusionment. Recent experiences from Austria and implications for countries in transformation,' Romanian Journal of Political Science, vol. 5, no.1, pp. 129-159.

Annan, K 2002, 'Kofi Annan's challenge to Silicon Valley,' November 5, viewed 18 Feb 2007, http://news.com.com/2010-1069-964507 html

Detar, J 2006, 'Intel Spurs PC Use in Developing World: "Discover the PC",' Investor's Business Daily, April 4, p.A06, quoting research from IDC.

Dunn, D 2006, 'Tech giants, nonprofits make ambitious push with cheap PCs,' Information Week, May 29, 2006. viewed 18 Feb 2007, http://www.informationweek.com/news/showArticle.jhtml?articleID=188500346

Garrett, L 2007, 'The challenge of global health,' Foreign Affairs, vol. 86, no. 1, pp. 14-40.

Gerrard, M 2001, 'Public-Private Partnerships,' Finance and Development, Sep, pp. 48-51.

Hart, S 2005, Capitalism at the Crossroads: the unlimited business opportunities in solving the world's most difficult problems, Wharton School Publishing, New Jersey.

Indjikian, R \& Siegel, D 2005, 'The Impact of Investment in IT on Economic Performance: Implications for Developing Countries,' World Development, vol.33, no. 5, pp.681-700.

Intel 2006, 'Case Study: WiMAX gives rural community a new voice,' viewed 23 Feb 2007, http://www.intel.com/intel/worldahead/casestudies_vietnam1.htm

International Telecommunications Union (ITU) 2006, 'Annex A: Proposed Topics in the 2006-2007 ITU New Initiatives Questionnaire,' Geneva, viewed 17 June 2007, http://www.itu.int/osg/spu/ni/ITUNewInitiativesQuestionnaireResults2006.pdf

Kanungo, S 2004, 'On the emancipatory role of rural information systems,' Information Technology \& People, vol. 17 , no. 4, pp. 407-422.

Lanvin, B 2005, 'The next billion,' Communications and Strategies. No 58, $2^{\text {nd }}$ Qtr, p.15.

Owen, D 2006, 'Vietnam LMI: Associated Working Papers,' December 20.

Owen, D 2007a, 'Expanding Rural Access: White Paper,' February 17, viewed 17 June 2007, http://www nextbillion.net/files/Expanding\%20Rural\%20Access-White\%20Paper-20Feb07_0.pdf

Owen, D 2007b, 'Expanding Rural Access: Associated Working Papers,' January 30.

Oyelaran-Oyeyinka, B \& Lal, K 2005, 'Internet diffusion in sub-Saharan Africa: a cross-country analysis,' Telecommunications Policy, no. 29, pp. 507-527.

Prahalad, CK 2005, The Fortune at the Bottom of the Pyramid, Wharton School Publishing, New Jersey.

Rosenau, PV 1999, 'The Strengths and Weaknesses of Public-Private Policy Partnerships,' American Behavioral Scientist, vol. 43, no.1, Sep, pp. 10-34.

Runde, D 2006, 'How to make development partnerships work,' OECD Observer, no. 255, May, pp. 29-31.

United Nations 2004, UN Global E-Government Readiness Report, 2004: Towards Access for Opportunity, Department of Economic and Social Affairs, Division for Public Administration and Development Management, New York.

United Nations Foundation \& World Economic Forum 2003, 'Public Private Partnerships: Meeting in the middle,' viewed 18 Feb 2007, https://www.weforum.org/pdf/Initiatives/GHI_2003_Meeting_in_the_middle.pdf

Weigel, G \& Waldburger, D (eds.) 2004, ICT4D: Connecting People for a Better World. Lessons, Innovations and Perpsectives of Information and Communication Technologies in Development, Swiss Agency for Development and Cooperation (SDC) and Global Knowledge Partnership (GKP), Berne, Switzerland.

World Bank 2003, 'ICT for Development Contributing to the Millennium Development Goals: Lessons Learned from Seventeen InfoDev Projects,' Washington, D.C., The World Bank.

World Bank 2006, 'Information and Communications for Development (IC4D) - Global Trends and Policies,' Washington, D.C., The World Bank. 